\title{
SOME INSIGHTS INTO FORMAMIDE FORMATION THROUGH GAS-PHASE REACTIONS IN THE INTERSTELLAR MEDIUM
}

\author{
Pilar Redondo, Carmen Barrientos, and Antonio Largo \\ Computational Chemistry Group, Departamento de Química Física, Facultad de Ciencias, Universidad de Valladolid, \\ E-47011 Valladolid, Spain; predondo@qf.uva.es \\ Received 2013 October 3; accepted 2013 November 21; published 2013 December 23
}

\begin{abstract}
We study the viability of different gas-phase ion-molecule reactions that could produce precursors of formamide in the interstellar medium. We analyze different reactions between cations containing a nitrogen atom $\left(\mathrm{NH}_{3}^{+}\right.$, $\mathrm{NH}_{4}^{+}, \mathrm{NH}_{3} \mathrm{OH}^{+}$, and $\left.\mathrm{NH}_{2} \mathrm{OH}^{+}\right)$and neutral molecules having one carbonyl group $\left(\mathrm{H}_{2} \mathrm{CO}\right.$ and $\left.\mathrm{HCOOH}\right)$. First, we report a theoretical estimation of the reaction enthalpies for the proposed processes. Second, for more favorable reactions, from a thermodynamic point of view, we perform a theoretical study of the potential energy surface. In particular, the more exothermic processes correspond to the reactions of ionized and protonated hydroxylamine with formaldehyde. In addition, a neutral-neutral reaction has also been considered. The analysis of the potential energy surfaces corresponding to these reactions shows that these processes present a net activation barrier and that they cannot be considered as a source of formamide in space.
\end{abstract}

Key words: astrobiology - astrochemistry - ISM: general - ISM: kinematics and dynamics - ISM: molecules molecular processes

Online-only material: color figures

\section{INTRODUCTION}

In the past few years, the availability of modern radio telescopes together with interferometry methods has made the detection of new species in space easier. More than 170 species have been detected in the interstellar medium and circumstellar envelopes, including simple organic molecules containing carbon, hydrogen, oxygen, and nitrogen elements. The interest in such organic molecules, especially those containing amino or carbonyl groups, is in part motivated by the fact that they could play a crucial role in the interstellar synthesis of biomolecules under prebiotic conditions. Understanding the formation of peptide bonds between amino acids is essential for a thorough knowledge of the processes of life. However, detection of the simplest amino acid, glycine, which has long been searched for in space, still remains to be confirmed (Ceccarelli et al. 2000; Hollis et al. 1980, 2003a, 2003b; Kuan et al. 2003; Snyder et al. 2005). Despite this unsuccessful search, the presence of glycine, and of other amino acids in space, cannot be ruled out. Even glycine is a relatively large molecule, and therefore, its rotational spectrum has relatively weak lines (Irvine 1998). The identification of more than 80 amino acids in meteorites, such as Murchison (Cooper et al. 1992), is a positive clue about the presence of amino acids in space. In contrast, molecules with a peptide bond $(\mathrm{NH}-\mathrm{C}=\mathrm{O})$, such as formamide (Rubin et al. 1971) and acetamide (Hollis et al. 2006), have been detected in interstellar clouds, and Halfen et al. (2011) recently highlighted their importance as prototypes for peptide bond formation. Because of these compounds' relatively large abundance, Halfen et al. suggest that they could be a possible source of larger peptide molecules that do not involve amino acids. The knowledge of the formation processes of these simple species could help us to understand the origin of more complex biomolecules based on peptide bonds such as proteins.

Formamide is the simplest molecule with a peptide bond. This makes it reactive at both amino and carbonyl sites and it could play a key role in the origin of life (Saladino et al.
2012). Several formation schemes of formamide in space have been proposed on ice of interstellar grains or in the gas phase. Woon (2001) made a theoretical study of the reactions between ices of $\mathrm{HCOOH}$ and $\mathrm{NH}_{3}$ to yield formamide, but the most favorable process was found to be formation of $\mathrm{NH}_{2} \mathrm{CH}(\mathrm{OH})_{2}$. In a recent experimental work, Jones et al. (2011) demonstrate that the formation of formamide in binary ice mixtures of $\mathrm{CO}$ and $\mathrm{NH}_{3}$ is possible when subjected to irradiation by energetic particles such as electrons. This binary mixture has also been previously studied in the solid state (Grim et al. 1989) and gas phase (Hubbard et al. 1975). Garrod et al. (2008) proposed a gas-grain chemical model where formamide is formed on grains at low temperature by hydrogenation of OCN. They also considered that formamide could be formed by the radical-neutral reaction between $\mathrm{H}_{2} \mathrm{CO}$ and $\mathrm{NH}_{2}$, but the activation energy for this reaction is $1025 \mathrm{~K}$. The gas-phase ion-molecule reaction between formaldehyde and protonated ammonia followed by dissociative electron recombination has been proposed (Quan \& Herbst 2007; Halfen et al. 2011), but experimental results are not available for this process.

The prebiotic interest of formamide is also related to the possibility of a partial decomposition to generate small molecules, such as $\mathrm{CO}, \mathrm{NH}_{3}, \mathrm{H}_{2} \mathrm{O}$, or $\mathrm{HCN}$, which are useful intermediates in the prebiotic synthesis of biomolecules. Recently, different decomposition channels of formamide have been reported in a theoretical study by Nguyen et al. (2011, 2013). From these results, we can conclude that formation of formamide from the direct products of its decomposition is not possible under interstellar conditions.

At present, no conclusive results have been obtained for the formation of formamide and, as Halfen et al. (2011) point out, more gas-phase and surface reaction results are needed to establish the synthetic routes. In this context, quantum-chemical studies can be valuable in ascertaining whether there are plausible and efficient synthetic routes toward interstellar species. Only exothermic and barrier-free processes could be efficient in interstellar conditions. Our aim in this work is to analyze 
theoretically the viability of different gas-phase ion-molecule reactions that could produce precursors of formamide in the interstellar medium. In particular, we consider processes between species that contain one nitrogen atom and a carbonyl group. We analyzed different ion-molecule reactions between cations $\left(\mathrm{NH}_{3}^{+}, \mathrm{NH}_{4}^{+}, \mathrm{NH}_{3} \mathrm{OH}^{+}\right.$, and $\left.\mathrm{NH}_{2} \mathrm{OH}^{+}\right)$and neutral molecules $\left(\mathrm{H}_{2} \mathrm{CO}\right.$ and $\left.\mathrm{HCOOH}\right)$. First, we report a theoretical estimation of the reaction enthalpies for the proposed processes. Second, for the more favorable, from a thermodynamic point of view, we perform a theoretical study of the potential energy surface to determine whether they are barrier-free processes. In particular, the more exothermic processes correspond with the reactions of ionized and protonated hydroxylamine with formaldehyde. In addition, we include the neutral-neutral reaction $\left(\mathrm{NH}_{2} \mathrm{OH}+\mathrm{H}_{2} \mathrm{CO}\right)$ to compare the effect of ionization and protonation on the viability of the process.

\section{COMPUTATIONAL METHODS}

Reaction enthalpies for the proposed processes are calculated using functional density theory for the optimization of the corresponding reactants and products. In particular, we used the B3LYP exchange-correlation functional, which includes the Lee-Yang-Parr (Lee et al. 1988) correlation functional in conjunction with a hybrid exchange functional that Becke first proposed (Becke 1988). In the B3LYP calculations, we used the Dunning's aug-cc-pVTZ (correlation-consistent polarized valence triple-zeta including diffuse functions) basis set (Dunning 1989; Woon \& Dunning 1993).

Geometrical optimizations for the reactants, intermediates, transition states, and products of the three potential energy surfaces studied in this work were performed at the Moller-Plesset level (MP2) also using the aug-cc-pVTZ basis set (Dunning 1989; Woon \& Dunning 1993).

Electronic energies were refined by performing single-point calculations at CCSD(T) level (Raghavachari et al. 1989) using the aug-cc-pVQZ basis set (Dunning 1989; Woon \& Dunning 1993), which has a quadruple-zeta character and includes both diffuse and polarization functions.

We carried out a vibrational analysis at the MP2/aug-ccpVTZ level to characterize the stationary points located on each potential surface as minima or transition states. These results also allow us an estimate of the zero-point vibrational energy (ZPVE) correction for each structure. In addition, we carried out intrinsic reaction coordinate (Fukui 1981) calculations to confirm that the obtained transition states correspond to the desired process.

All calculations reported in this work were carried out with the Gaussian-09 program package (Frisch et al. 2009).

\section{RESULTS AND DISCUSSION}

\subsection{Thermodynamic Results}

We have considered ion-molecule reactions between cations containing a nitrogen atom $\left(\mathrm{NH}_{3}^{+}, \mathrm{NH}_{4}^{+}, \mathrm{NH}_{3} \mathrm{OH}^{+}\right.$, and $\mathrm{NH}_{2} \mathrm{OH}^{+}$) and neutral molecules having one carbonyl group $\left(\mathrm{H}_{2} \mathrm{CO}\right.$ and $\left.\mathrm{HCOOH}\right)$. Among the selected species, $\mathrm{NH}_{4}^{+}$ (Cernicharo et al. 2013), $\mathrm{H}_{2} \mathrm{CO}$ (Synder et al. 1969), and $\mathrm{HCOOH}$ (Winnewisser \& Churchwell 1975) were detected in interstellar space. The $\mathrm{NH}_{3}^{+}$cation was not detected in space; however, the neutral molecule, $\mathrm{NH}_{3}$, was observed (Cheung et al. 1968), and it can be easily ionized in interstellar conditions (IP $=10.07$ eV; NIST Chemistry WebBook 2009). However, neutral, protonated, and ionized hydroxylamine were not
Table 1

Reaction Enthalpies for Some Gas-phase Reactions Given Formamide Precursors Calculated at $0 \mathrm{~K}$

\begin{tabular}{|c|c|c|}
\hline Reactions & $\begin{array}{c}\Delta \mathrm{H}^{\mathrm{a}} \\
\left(\mathrm{kcal} \mathrm{mol}^{-1}\right)\end{array}$ & $\begin{array}{c}\Delta \mathrm{H}^{\mathrm{b}} \\
\left(\mathrm{kcal} \mathrm{mol}^{-1}\right)\end{array}$ \\
\hline $\begin{aligned} \mathrm{NH}_{4}^{+}+\mathrm{HCOOH} & \rightarrow \mathrm{NH}_{2} \mathrm{CHOH}^{+}+\mathrm{H}_{2} \mathrm{O} \\
& \rightarrow \mathrm{NH}_{3}+\mathrm{HCOOHH}^{+}\end{aligned}$ & $\begin{array}{r}1.65 \\
29.13\end{array}$ & $\begin{array}{r}2.77 \\
30.10\end{array}$ \\
\hline $\begin{aligned} \mathrm{NH}_{4}^{+}+\mathrm{H}_{2} \mathrm{CO} & \rightarrow \mathrm{NH}_{2} \mathrm{CHOH}^{+}+\mathrm{H}_{2} \\
& \rightarrow \mathrm{H}_{2} \mathrm{COH}^{+}+\mathrm{NH}_{3}\end{aligned}$ & $\begin{array}{r}-5.16 \\
33.15\end{array}$ & $\begin{array}{r}-3.06 \\
33.17\end{array}$ \\
\hline $\mathrm{NH}_{3}^{+}+\mathrm{HCOOH} \rightarrow \mathrm{NH}_{2} \mathrm{CHO}^{+}+\mathrm{H}_{2} \mathrm{O}$ & -4.12 & -0.52 \\
\hline $\begin{aligned} \mathrm{NH}_{3} \mathrm{OH}^{+}+\mathrm{HCO} & \rightarrow \mathrm{NH}_{2} \mathrm{CHO}^{+}+\mathrm{H}_{2} \mathrm{O} \\
& \rightarrow \mathrm{NH}_{2} \mathrm{OH}^{+}+\mathrm{H}_{2} \mathrm{CO} \\
& \rightarrow \mathrm{NH}_{2} \mathrm{OH}+\mathrm{H}_{2} \mathrm{CO}^{+}\end{aligned}$ & $\begin{array}{r}-39.51 \\
3.52 \\
42.26\end{array}$ & $\begin{array}{r}-37.38 \\
5.98 \\
44.27\end{array}$ \\
\hline $\mathrm{NH}_{2} \mathrm{OH}^{+}+\mathrm{HCO} \rightarrow \mathrm{NH}_{2} \mathrm{CHO}^{+}+\mathrm{HO}$ & -13.18 & -12.92 \\
\hline $\begin{aligned} \mathrm{NH}_{3} \mathrm{OH}^{+}+\mathrm{H}_{2} \mathrm{CO} & \rightarrow \mathrm{NH}_{2} \mathrm{CHOH}^{+}+\mathrm{H}_{2} \mathrm{O} \\
& \rightarrow \mathrm{NH}_{2} \mathrm{OH}+\mathrm{H}_{2} \mathrm{COH}^{+}\end{aligned}$ & $\begin{array}{r}-70.41 \\
24.63\end{array}$ & $\begin{array}{r}-69.64 \\
24.75\end{array}$ \\
\hline $\mathrm{NH}_{2} \mathrm{OH}+\mathrm{H}_{2} \mathrm{CO} \rightarrow \mathrm{NH}_{2} \mathrm{CHO}+\mathrm{H}_{2} \mathrm{O}$ & -65.89 & -66.22 \\
\hline $\mathrm{NH}_{2} \mathrm{OH}^{+}+\mathrm{H}_{2} \mathrm{CO} \rightarrow \mathrm{NH}_{2} \mathrm{CHO}^{+}+\mathrm{H}_{2} \mathrm{O}$ & -43.03 & -43.34 \\
\hline
\end{tabular}

Notes.

${ }^{\text {a }}$ Calculated at the B3LYP/aug-cc-pVTZ level (ZPVE included).

b Calculated at the $\operatorname{CCSD(T)/aug-cc-pVQZ//B3LYP/aug-cc-pVTZ~level~}$ (ZPVE included).

detected in space but are considered plausible interstellar molecules. Furthermore, different experimental studies produced hydroxylamine by irradiation of ice mixtures simulating interstellar grains (Nishi et al. 1984; Zheng \& Kaiser 2010; Congiu et al. 2012). Once hydroxylamine is formed, it can be ionized by photons or electron transfer $(\mathrm{IP}=10.06 \mathrm{eV}$; Lias et al. 1988) or can be protonated because of its high proton affinity $\left(\mathrm{PA}=193.5 \mathrm{kcal} \mathrm{mol}^{-1}\right.$; Boulet et al. 1999). Another important aspect is that both protonated and ionized hydroxylamine, $\mathrm{NH}_{2} \mathrm{OH}^{+}$and $\mathrm{NH}_{3} \mathrm{OH}^{+}$, do not react with molecular hydrogen, the most abundant molecule in the interstellar medium (Largo et al. 2009).

Table 1 shows the reaction enthalpies for the proposed reactions. In general, the results computed at both levels of theory are similar. All of the electron-exchange reactions are endothermic and are not viable in space; therefore, they are not reported in Table 1. Proton-transfer reactions are also not competitive processes for $\mathrm{NH}_{4}^{+}$and $\mathrm{NH}_{3} \mathrm{OH}^{+}$reactants, because, as Table 1 shows, they show a clear endothermicity. With the exception of the reaction between $\mathrm{NH}_{4}^{+}$and formic acid, all of the studied reactions are exothermic for the formation of formamide precursors. In general, Table 1 shows that the reactions initiated by cations derived from ammonium with carbonyl compounds are less exothermic than are those initiated by hydroxylamine derivatives. In particular, the most favorable reactions from a thermodynamic point of view are reactions of ionized and protonated hydroxylamine with formaldehyde $(\Delta H=-43.34$ and $-69.64 \mathrm{kcal} \mathrm{mol}^{-1}$ respectively, at the $\operatorname{CCSD}(\mathrm{T}) /$ aug-ccpVQZ//B3LYP/aug-cc-pVTZ level). Thus, in the next section, we focus on the study of the potential energy surface for these reactions, which are the most exothermic processes studied in the present work. This will help us to establish whether the formation of formamide precursors are barrier-free processes and therefore viable in the interstellar medium. In addition, we also include the neutral reaction, which is clearly an exothermic process for the formation of formamide $(\Delta H=$ $-66.22 \mathrm{kcal} \mathrm{mol}^{-1}$ at the CCSD(T)/aug-cc-pVQZ//B3LYP/ aug-cc-pVTZ level). This allows us to discuss how this kind of processes could be favored upon ionization or protonation. 


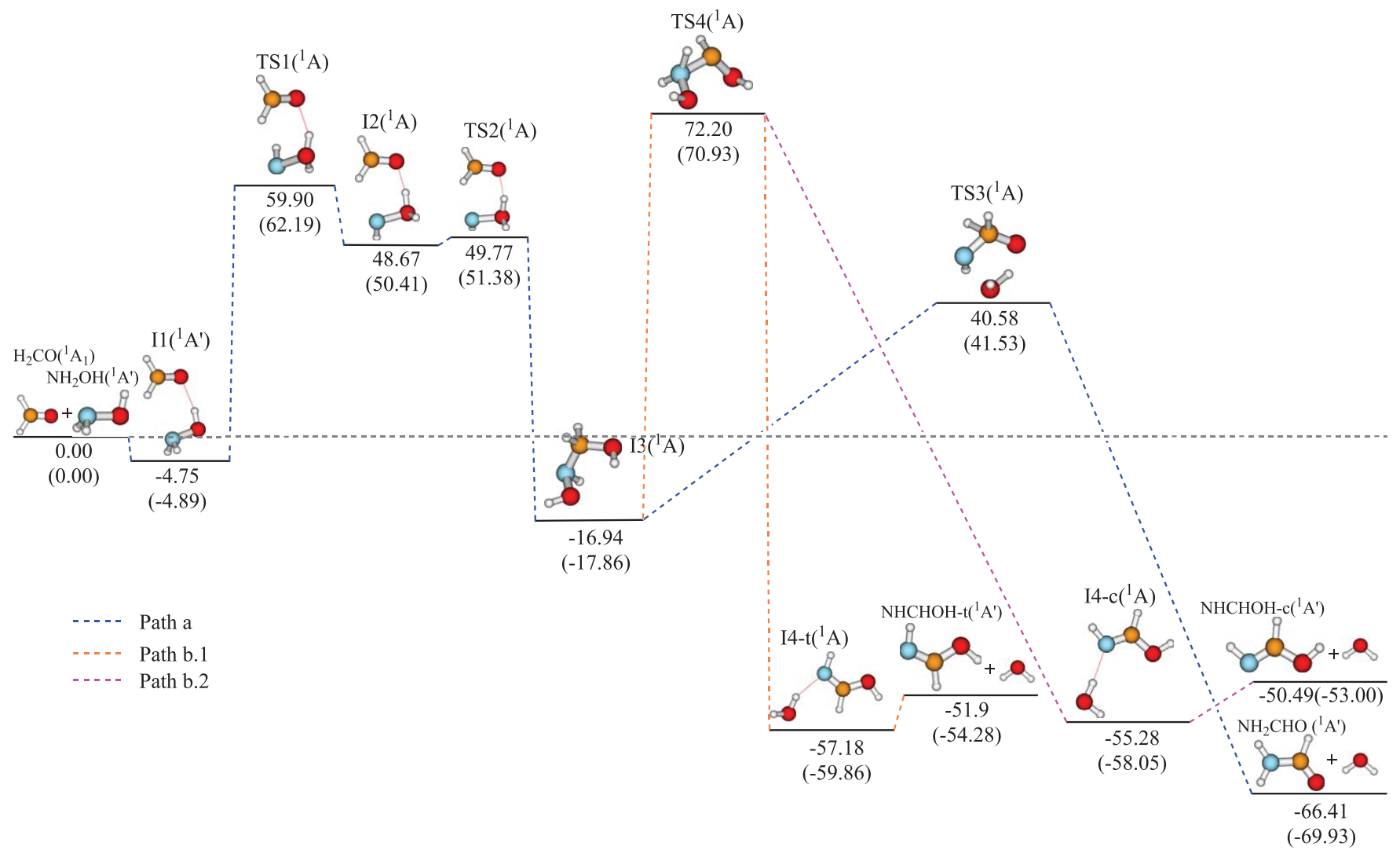

Figure 1. Energy profile, in kcal mol ${ }^{-1}$, for the reaction of $\mathrm{NH}_{2} \mathrm{OH}$ with $\mathrm{H}_{2} \mathrm{CO}$ at the CCSD(T)/aug-cc-pVQZ//MP2/aug-cc-pVTZ and MP2/aug-cc-pVTZ (in parentheses) levels. Zero-point vibrational energy differences are included.

(A color version of this figure is available in the online journal.)

The reactions of formic acid with $\mathrm{NH}_{3}^{+}$and $\mathrm{NH}_{4}^{+}$are also viable in space from a thermodynamic point of view. However, to establish their possible role in the formation of formamide, an exhaustive analysis of their corresponding potential energy surface is necessary.

\section{$3.2 \mathrm{NH}_{2} \mathrm{OH}+\mathrm{H}_{2} \mathrm{CO}$ Reaction}

The possible intermediate species, products, and the relevant transition states of the reaction of $\mathrm{NH}_{2} \mathrm{OH}+\mathrm{H}_{2} \mathrm{CO}$ have been characterized. In Figure 1, the energy profile for this reaction is reported. Given the multiplicity of the reactants $\left(\mathrm{NH}_{2} \mathrm{OH}\left({ }^{1} \mathrm{~A}^{\prime}\right)\right.$, and $\left.\mathrm{H}_{2} \mathrm{CO}\left({ }^{1} \mathrm{~A}_{1}\right)\right)$, the reaction should take place on the singlet potential energy surface. All transition states located have an imaginary frequency that is associated in each case with the corresponding reaction coordinate. Figure 1 shows that similar energy profiles are obtained at MP2 and $\operatorname{CCSD}(\mathrm{T})$ levels. The reaction enthalpies for the formation of formamide computed at both $\operatorname{CCSD(T)/aug-cc-pVQZ//B3LYP/aug-cc-pVTZ~and~}$ CCSD(T)/aug-cc-pVQZ//MP2/aug-cc-pVTZ levels of theory are almost identical (B3LYP: $-66.22 \mathrm{kcal} \mathrm{mol}^{-1}$; see Table 1 and MP2: $-66.41 \mathrm{kcal} \mathrm{mol}^{-1}$; see Figure 1). We found a similar behavior for the reactions of protonated and ionized hydroxylamine with $\mathrm{H}_{2} \mathrm{CO}$.

Different paths giving formamide and its isomer formimidic acid in two different conformations are characterized. Nguyen et al. (2011) studied the interconversion between the different isomers of formamide and showed that it implies significant energy barriers.

The mechanism for the reaction of hydroxylamine with formaldehyde starts with the formation of a pre-reaction com- plex I $1\left({ }^{1} \mathrm{~A}^{\prime}\right)$, which results from the interaction of the $\mathrm{OH}$ group with the carbonyl oxygen of formaldehyde. Then, the 1,2-proton shift from the nitrogen to the oxygen atom takes place through the transition state $\operatorname{TS} 1\left({ }^{1} \mathrm{~A}\right)$ and produces a second intermediate, I $2\left({ }^{1} \mathrm{~A}\right)$. It progresses through TS $2\left({ }^{1} \mathrm{~A}\right)$, giving I $3\left({ }^{1} \mathrm{~A}\right)$, where the $\mathrm{N}-\mathrm{C}$ bond is formed. From I3, we can reach formamide through $\mathrm{TS} 3\left({ }^{1} \mathrm{~A}\right)$. In this transition state, the hydrogen migration from the carbon to the nitrogen atom, and the elimination of a water molecule take place. This process (path a, Figure 1) can be summarized as follows:

$$
\begin{aligned}
\mathrm{H}_{2} \mathrm{CO} & \left({ }^{1} \mathrm{~A}_{1}\right)+\mathrm{NH}_{2} \mathrm{OH}\left({ }^{1} \mathrm{~A}^{\prime}\right) \rightarrow \mathrm{I} 1\left({ }^{1} \mathrm{~A}^{\prime}\right) \rightarrow \operatorname{TS} 1\left({ }^{1} \mathrm{~A}\right) \\
& \rightarrow \mathrm{I} 2\left({ }^{1} \mathrm{~A}\right) \rightarrow \operatorname{TS} 2\left({ }^{1} \mathrm{~A}\right) \rightarrow \mathrm{I} 3\left({ }^{1} \mathrm{~A}\right) \rightarrow \operatorname{TS} 3\left({ }^{1} \mathrm{~A}\right) \\
& \rightarrow \mathrm{NH}_{2} \mathrm{CHO}\left({ }^{1} \mathrm{~A}^{\prime}\right)+\mathrm{H}_{2} \mathrm{O} \quad \text { (Path a). }
\end{aligned}
$$

The global process is exothermic, $\Delta H=-66.41 \mathrm{kcal} \mathrm{mol}^{-1}$ at the CCSD(T)/aug-cc-pVQZ level, but presents a net activation barrier of $59.90 \mathrm{kcal} \mathrm{mol}^{-1}$ at the CCSD(T)/aug-cc-pVQZ level. Therefore, it is not feasible under the interstellar conditions. The two conformers of formimidic acid can be reached from I3 through TS4 $\left({ }^{1} \mathrm{~A}\right)$, which is located $72.20 \mathrm{kcal} \mathrm{mol}^{-1}$ above the reactants:

$$
\begin{aligned}
\mathrm{I} 3\left({ }^{1} \mathrm{~A}\right) & \rightarrow \mathrm{TS} 4\left({ }^{1} \mathrm{~A}\right) \rightarrow \mathrm{I} 4-\mathrm{t}\left({ }^{1} \mathrm{~A}\right) \\
& \rightarrow \mathrm{NHCHOH}-\mathrm{t}\left({ }^{1} \mathrm{~A}^{\prime}\right)+\mathrm{H}_{2} \mathrm{O} \quad(\text { Path b. }) \\
\mathrm{I} 3\left({ }^{1} \mathrm{~A}\right) & \rightarrow \mathrm{TS} 4\left({ }^{1} \mathrm{~A}\right) \rightarrow \mathrm{I} 4-\mathrm{c}\left({ }^{1} \mathrm{~A}\right) \\
& \rightarrow \text { NHCHOH-c }\left({ }^{1} \mathrm{~A}^{\prime}\right)+\mathrm{H}_{2} \mathrm{O} \quad \text { (Path b.2) }
\end{aligned}
$$




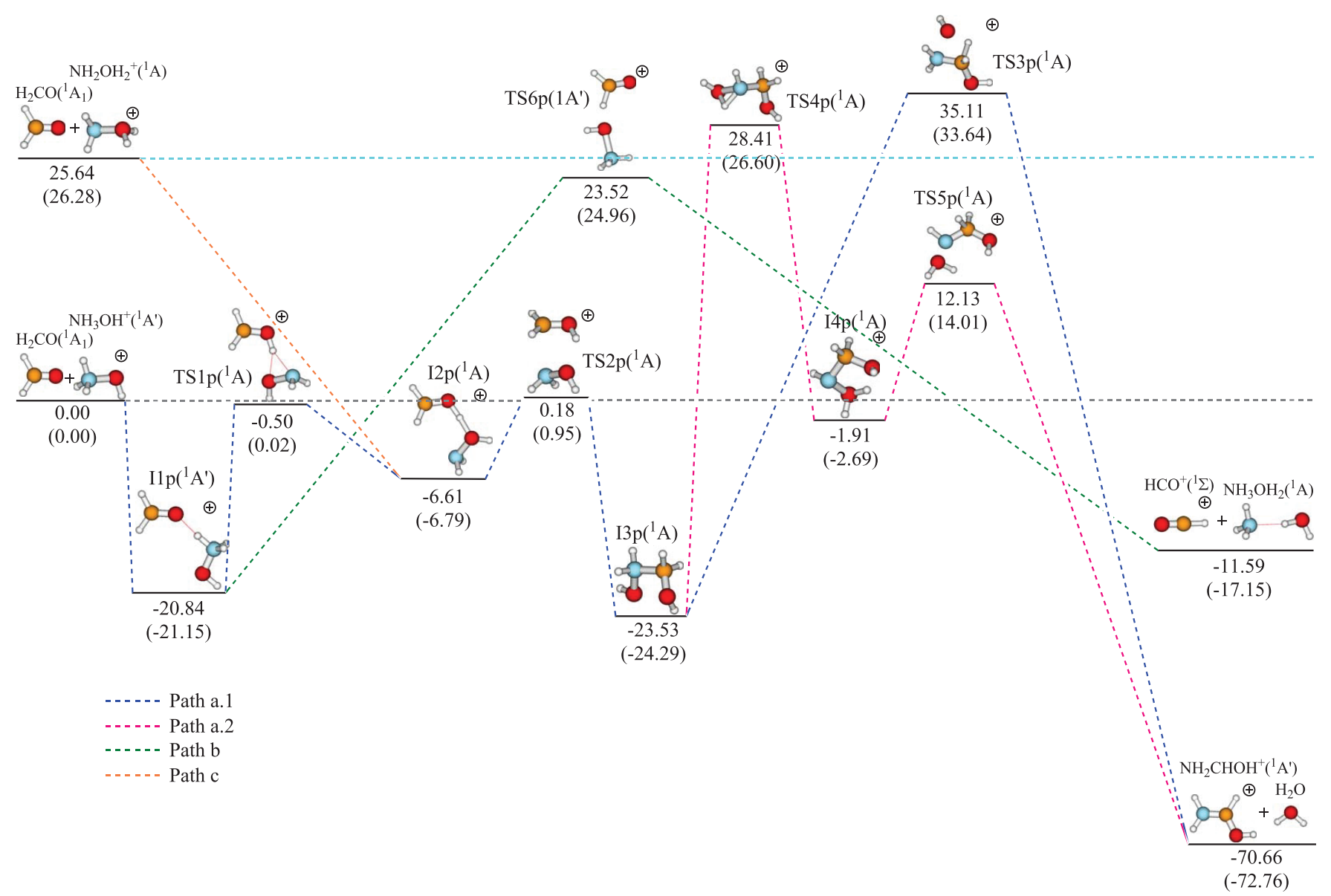

Figure 2. Energy profile, in kcal mol ${ }^{-1}$, for the reaction of $\mathrm{NH}_{2} \mathrm{OH}^{+}$with $\mathrm{H}_{2} \mathrm{CO}$ at the $\mathrm{CCSD}(\mathrm{T}) /$ aug-cc-pVQZ//MP2/aug-cc-pVTZ and MP2/aug-cc-pVTZ (in parentheses) levels. Zero-point vibrational energy differences are included.

(A color version of this figure is available in the online journal.)

Both processes are clearly exothermic $(-54.28$ and $-53.00 \mathrm{kcal} \mathrm{mol}^{-1}$ at the $\operatorname{CCSD}(\mathrm{T}) /$ aug-cc-pVQZ//MP2/augcc-pVTZ level, respectively; see Figure 1), but with a net activation barrier $\left(-70.93 \mathrm{kcal} \mathrm{mol}^{-1}\right.$ at the CCSD(T)/aug-cc-pVQZ/ /MP2/aug-cc-pVTZ level; see Figure 1) making paths b.1 and b. 2 not viable in the interstellar medium. From the analysis of the potential energy surface of the reaction between formaldehyde and hydroxylamine, we can conclude that even though formation of formamide and its isomers are exothermic processes, they present a net activation barrier, and this reaction cannot be considered as a source of formamide in space.

\section{3. $\mathrm{NH}_{3} \mathrm{OH}^{+}+\mathrm{H}_{2} \mathrm{CO}$ Reaction}

The corresponding potential energy surface of the reaction between protonated hydroxylamine and formaldehyde is shown in Figure 2. This reaction takes place on the singlet potential surface, given the multiplicity of reactants $\left(\mathrm{H}_{2} \mathrm{CO}\left({ }^{1} \mathrm{~A}_{1}\right)\right.$ and $\mathrm{NH}_{3} \mathrm{OH}^{+}\left({ }^{1} \mathrm{~A}^{\prime}\right)$ ). Figure 2 shows that formation of protonated formamide starts with the direct formation of the electrostatic complex I1p $\left({ }^{1} \mathrm{~A}^{\prime}\right)$, which implies the interaction of the $\mathrm{NH}_{3}$ group with the carbonyl oxygen of formaldehyde. Then, the hydrogen migration from the nitrogen to the oxygen atom takes place through the transition state $\operatorname{TS} 1 \mathrm{p}\left({ }^{1} \mathrm{~A}\right)$ leading to a second intermediate, I2p $\left({ }^{1} \mathrm{~A}\right)$. In this intermediate, the carbonylic oxygen interacts with the $\mathrm{OH}_{2}$ group of protonated hydroxylamine. Formation of the $\mathrm{C}-\mathrm{N}$ bond in intermediate $\mathrm{I} 3 \mathrm{p}\left({ }^{1} \mathrm{~A}\right)$ is reached through TS2 $p\left({ }^{1} A\right)$. Starting for $\operatorname{I3} p\left({ }^{1} A\right)$, formation of protonated formamide can take place through two routes: (1) from path a.1, the products are reached through $\operatorname{TS} 3 \mathrm{p}\left({ }^{1} \mathrm{~A}\right)$ where the migration of a hydrogen atom from carbon to oxygen and the elimination of one $\mathrm{H}_{2} \mathrm{O}$ molecule take place simultaneously; and (2) from path a.2, which implies a two-step mechanism: first, the hydrogen migration from nitrogen atom to oxygen leads to intermediate I4p $\left({ }^{1} A\right)$, involving TS4 $\left({ }^{1} A\right)$. Second, the formation of protonated formamide through $\operatorname{TS} 5 \mathrm{p}\left({ }^{1} \mathrm{~A}\right)$, where the hydrogen migration from carbon to nitrogen and $\mathrm{H}_{2} \mathrm{O}$ elimination take place. These processes can be summarized as follows:

$$
\begin{aligned}
& \mathrm{H}_{2} \mathrm{CO}\left({ }^{1} \mathrm{~A}_{1}\right)+\mathrm{NH}_{3} \mathrm{OH}^{+}\left({ }^{1} \mathrm{~A}^{\prime}\right) \rightarrow \mathrm{I} 1 \mathrm{p}\left({ }^{1} \mathrm{~A}^{\prime}\right) \rightarrow \mathrm{TS} 1 \mathrm{p}\left({ }^{1} \mathrm{~A}\right) \\
& \rightarrow \mathrm{I} 2 \mathrm{p}\left({ }^{1} \mathrm{~A}\right) \rightarrow \mathrm{TS} 2 \mathrm{p}\left({ }^{1} \mathrm{~A}\right) \rightarrow \\
& \mathrm{I} 3 \mathrm{p}\left({ }^{1} \mathrm{~A}\right) \rightarrow\left\{\begin{aligned}
\mathrm{TS} 3 \mathrm{p}\left({ }^{1} \mathrm{~A}\right) & \rightarrow \mathrm{NH}_{2} \mathrm{CHOH}^{+}\left({ }^{1} \mathrm{~A}^{\prime}\right)+\mathrm{H}_{2} \mathrm{O} \text { (Path a.1) } \\
\mathrm{TS} 4 \mathrm{p}\left({ }^{1} \mathrm{~A}\right) & \rightarrow \mathrm{I} 4 \mathrm{p}\left({ }^{1} \mathrm{~A}\right) \rightarrow \mathrm{TS} 5 \mathrm{p}\left({ }^{1} \mathrm{~A}\right) \\
& \rightarrow \mathrm{NH}_{2} \mathrm{CHOH}^{+}\left({ }^{1} \mathrm{~A}^{\prime}\right)+\mathrm{H}_{2} \mathrm{O} \text { (Path a.2). }
\end{aligned}\right.
\end{aligned}
$$

Figure 2 shows that, even though formation of protonated formamide is clearly an exothermic process $\left(-70.66 \mathrm{kcal} \mathrm{mol}^{-1}\right.$ at the CCSD(T)/aug-cc-pVQZ//MP2/aug-cc-pVTZ level), both paths present a relatively high activation barrier (35.11 and $28.41 \mathrm{kcal} \mathrm{mol}^{-1}$ at the $\operatorname{CCSD}(\mathrm{T}) /$ aug-cc-pVQZ//MP2/augcc-pVTZ level, respectively). Consequently, they cannot be a source of formamide in the interstellar medium.

Isomer I1 $\left.\mathrm{p}^{1}{ }^{\mathrm{A}} \mathrm{A}^{\prime}\right)$ can also evolve to the formation of $\mathrm{HCO}^{+}+$ $\mathrm{NH}_{3} \mathrm{OH}_{2}$ through the transition state $\operatorname{TS} 6 \mathrm{p}\left({ }^{1} \mathrm{~A}^{\prime}\right)$ (path b, Figure 2), which is located $23.52 \mathrm{kcal} \mathrm{mol}^{-1}$ above the reactants 


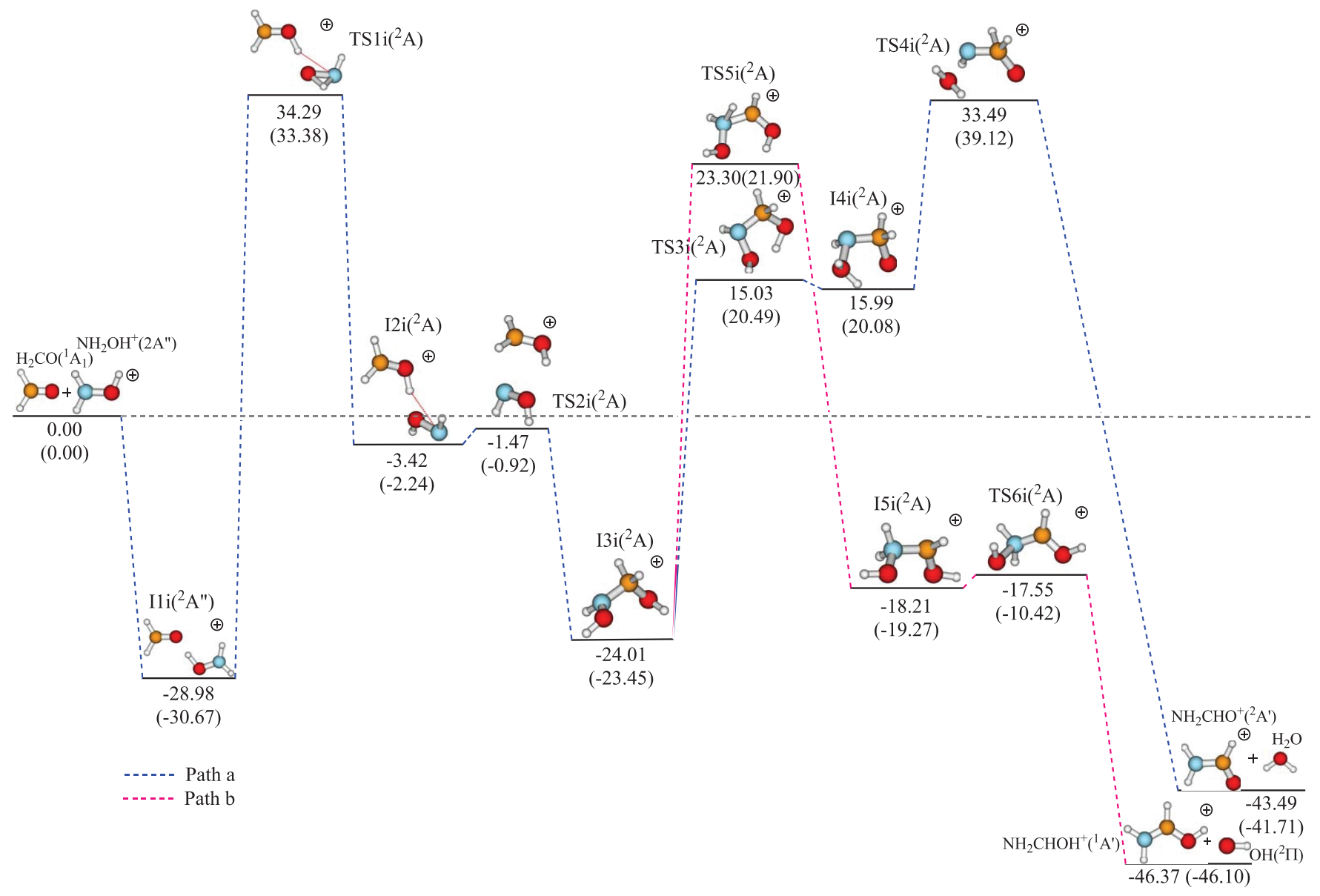

Figure 3. Energy profile, in kcal mol ${ }^{-1}$, for the reaction of $\mathrm{NH}_{3} \mathrm{OH}^{+}$with $\mathrm{H}_{2} \mathrm{CO}$ at the $\mathrm{CCSD}(\mathrm{T}) /$ aug-cc-pVQZ//MP2/aug-cc-pVTZ and MP2/aug-cc-pVTZ (in parentheses) levels. Zero-point vibrational energy differences are included.

(A color version of this figure is available in the online journal.)

at the CCSD(T)/aug-cc-pVQZ//MP2/aug-cc-pVTZ level, and make this process not feasible under interstellar conditions.

The protonation process of hydroxylamine generates two isomers $\mathrm{NH}_{3} \mathrm{OH}^{+}$(the most stable one) and $\mathrm{NH}_{2} \mathrm{OH}_{2}^{+}$, according to the results that Bohme et al. reported (Snow et al. 2007). Both isomers may coexist in the interstellar medium, as previously discussed by Boulet et al. (1999). Therefore, both isomers could be considered as reactants in this reaction. The ion-molecule interaction between the less stable isomer $\mathrm{NH}_{2} \mathrm{OH}_{2}^{+}$with formaldehyde leads to intermediate I2p $\left({ }^{1} \mathrm{~A}\right)$ (path c, Figure 2), which can evolve as described previously. From these reactants, formation of protonated formamide presents a net activation barrier of 9.47 and $2.77 \mathrm{kcal} \mathrm{mol}^{-1}$ for path a. 1 and a.2 at the CCSD(T)/aug-cc-pVQZ//MP2/aug-ccpVTZ level, respectively. The barrier found for the process a. 2 is relatively small; thus, we have reoptimized the geometry of the transition state $\operatorname{TS} 4 \mathrm{p}\left({ }^{1} \mathrm{~A}\right)$ at $\mathrm{CCSD} /$ aug-cc-pVDZ and CCSD/ cc-pVDZ levels, and the relative energy of the transition state TS4p is increased in 0.2 and $0.5 \mathrm{kcal} \mathrm{mol}^{-1}$, respectively. These results confirm that the process will not be reliable in interstellar conditions. However, formation of $\mathrm{HCO}^{+}+\mathrm{NH}_{3} \mathrm{OH}_{2}$ is an exothermic and barrier-free process and therefore the only feasible process under interstellar conditions.

The detailed analysis of the potential energy surface shows that the reaction of both isomers of protonated hydroxylamine with formaldehyde, despite being a clearly exothermic process, do not contribute to the formation of protonated formaldehyde in the interstellar space because they involve net activation barriers.

\section{4. $\mathrm{NH}_{2} \mathrm{OH}^{+}+\mathrm{H}_{2} \mathrm{CO}$ Reaction}

Figure 3 shows the profile for the reaction of ionized hydroxylamine with formaldehyde including the possible intermediate species, products, and the relevant transition states. In this case, given the multiplicity of reactants $\left(\mathrm{H}_{2} \mathrm{CO}\left({ }^{1} \mathrm{~A}_{1}\right)\right.$ and $\left.\mathrm{NH}_{2} \mathrm{OH}^{+}\left({ }^{2} \mathrm{~A}^{\prime \prime}\right)\right)$ the reaction takes place on the doublet potential energy surface. For this reaction we have found that the formation of both ionized and protonated formamide are clearly exothermic processes $\left(\Delta H\right.$ are -43.49 and $-46.37 \mathrm{kcal} \mathrm{mol}^{-1}$ at the $\operatorname{CCSD}(\mathrm{T}) /$ aug-cc-pVQZ//MP2/aug-cc-pVTZ level, respectively). Figure 3 shows that both processes begin with the same initial steps. The reaction starts with the formation of the ion-molecule intermediate $\operatorname{I1}\left({ }^{2} \mathrm{~A}^{\prime \prime}\right)$ through a barrierless process. Then, the hydrogen atom migration from the nitrogen atom to the oxygen one takes place in transition state $\mathrm{TS}_{1} \mathrm{i}\left({ }^{2} \mathrm{~A}\right)$ and leads to intermediate $\mathrm{I} 2 \mathrm{i}\left({ }^{2} \mathrm{~A}\right)$. After that, formation of the $\mathrm{C}-\mathrm{N}$ bond in intermediate $\mathrm{I} 3 \mathrm{i}\left({ }^{2} \mathrm{~A}\right)$ takes place through transition state TS2i $\left({ }^{2} \mathrm{~A}\right)$. Intermediate $\mathrm{I} 3 \mathrm{i}\left({ }^{2} \mathrm{~A}\right)$ can progress in two ways, giving either ionized or protonated formamide. A hydrogen transfer from the hydroxyl group to the oxygen atom bonded to the nitrogen atom in $\mathrm{I} 3 \mathrm{i}\left({ }^{2} \mathrm{~A}\right)$ leads to $\mathrm{I} 4 \mathrm{i}\left({ }^{2} \mathrm{~A}\right)$. Once this intermediate is formed, the simultaneous $\mathrm{H}_{2} \mathrm{O}$ elimination and hydrogen atom 
migration from carbon to nitrogen leads to ionized formamide. In this process, $\mathrm{TS} 3 \mathrm{i}\left({ }^{2} \mathrm{~A}\right)$ and $\mathrm{TS} 4 \mathrm{i}\left({ }^{2} \mathrm{~A}\right)$ are implicated. This path is similar to path a.2 for the reaction of protonated hydroxylamine with $\mathrm{H}_{2} \mathrm{CO}$ (see Figure 2), but in the case of the reaction with ionized hydroxylamine, the corresponding path a.1 was not located. In contrast, when $\mathrm{I} 3 \mathrm{i}\left({ }^{2} \mathrm{~A}\right)$ evolves through TS5i $\left({ }^{2} \mathrm{~A}\right)$ to give $\mathrm{I} 5 \mathrm{i}\left({ }^{2} \mathrm{~A}\right)$, a hydrogen passes from the carbon atom to the nitrogen one. Then, the elimination of $\mathrm{OH}$ through transition state TS6i $\left({ }^{2} \mathrm{~A}\right)$ leads to protonated formamide. Both processes can be summarized as follows:

$$
\begin{aligned}
\mathrm{H}_{2} \mathrm{CO}\left({ }^{1} \mathrm{~A}_{1}\right)+\mathrm{NH}_{2} \mathrm{OH}^{+}\left({ }^{2} \mathrm{~A}^{\prime \prime}\right) & \rightarrow \mathrm{I} 1 \mathrm{i}\left({ }^{2} \mathrm{~A}^{\prime \prime}\right) \rightarrow \mathrm{TS} 1 \mathrm{ii}\left({ }^{2} \mathrm{~A}\right) \\
& \rightarrow \mathrm{I} 2 \mathrm{i}\left({ }^{2} \mathrm{~A}\right) \rightarrow \mathrm{TS} 2 \mathrm{i}\left({ }^{2} \mathrm{~A}\right) \rightarrow \\
& \\
& \left.\rightarrow{ }^{2} \mathrm{~A}\right) \rightarrow\left\{\begin{aligned}
& \mathrm{TS} 3 \mathrm{i}\left({ }^{2} \mathrm{~A}\right)\left.\mathrm{I} 4{ }^{2} \mathrm{~A}\right) \rightarrow \mathrm{TS} 4 \mathrm{i}\left({ }^{2} \mathrm{~A}\right) \\
& \rightarrow \mathrm{NH}_{2} \mathrm{COH}^{+}\left({ }^{2} \mathrm{~A}^{\prime}\right)+\mathrm{H}_{2} \mathrm{O} \quad \text { (Path a) } \\
& \mathrm{TS} 5 \mathrm{i}\left({ }^{2} \mathrm{~A}\right) \rightarrow \mathrm{I} 5 \mathrm{i}\left({ }^{1} \mathrm{~A}\right) \rightarrow \mathrm{TS}^{2}\left({ }^{2} \mathrm{~A}\right) \\
& \rightarrow \mathrm{NH}_{2} \mathrm{CHOH}^{+}\left({ }^{1} \mathrm{~A}^{\prime}\right)+\mathrm{OH}\left({ }^{2} \Pi\right) \\
& \text { (Path b) }
\end{aligned}\right.
\end{aligned}
$$

In both paths, the limiting step is the isomerization of intermediate $\mathrm{I} 1 \mathrm{i}\left({ }^{2} \mathrm{~A}^{\prime \prime}\right)$ to $\mathrm{I} 2 \mathrm{i}\left({ }^{2} \mathrm{~A}\right)$ that takes place through transition state $\operatorname{TS} 1 \mathrm{i}\left({ }^{2} \mathrm{~A}\right)$, which is located $34.29 \mathrm{kcal} \mathrm{mol}^{-1}$ above the reactants at the CCSD(T)/aug-cc-pVQZ level. Therefore, both processes are exothermic but present a net activation barrier, and they will not be feasible under the interstellar conditions.

Last, we can compare the results obtained for the reactions of $\mathrm{H}_{2} \mathrm{CO}$ with neutral, protonated and ionized hydroxylamine. In all cases, the formation of formamide precursors is an exothermic process, but their net activation barriers make them not viable under interstellar conditions. The activation barrier is lowered with respect to the neutral-neutral reaction $\left(\approx 20-30 \mathrm{kcal} \mathrm{mol}^{-1}\right.$ ) when ionized and protonated hydroxylamine are considered as reactants. A similar result was found in our previous study of the reactions of acetic acid with hydroxylamine and its ionized and protonated derivatives (Barrientos et al. 2012).

\section{CONCLUSIONS}

We calculated the reaction enthalpies for different ion-molecule reactions between cations containing a nitrogen atom $\left(\mathrm{NH}_{3}^{+}, \mathrm{NH}_{4}^{+}, \mathrm{NH}_{3} \mathrm{OH}^{+}\right.$, and $\left.\mathrm{NH}_{2} \mathrm{OH}^{+}\right)$and neutral molecules having a carbonyl group $\left(\mathrm{H}_{2} \mathrm{CO}\right.$ and $\left.\mathrm{HCOOH}\right)$. We found that the reactions initiated by cations derived from ammonium with carbonyl compounds are less exothermic than are those initiated by hydroxylamine derivatives. In particular, the most favorable reactions from a thermodynamic point of view are the reactions of ionized and protonated hydroxylamine with formaldehyde. Therefore, a theoretical study of the potential energy surface for the reactions of formaldehyde with hydroxylamine and its protonated and ionized derivatives has been carried out to clarify the relevance of these processes in the formation of formamide under the conditions of the interstellar medium. The possible intermediate species and the relevant transition states for these reactions have been characterized.

From the analysis of the potential energy surface of the reaction between formaldehyde and hydroxylamine, we can conclude that even though formation of formamide and the two conformers of formimidic acid are exothermic processes, they present net activation barriers $\left(59.90\right.$ and $72.20 \mathrm{kcal} \mathrm{mol}^{-1}$ at the $\operatorname{CCSD}(\mathrm{T}) /$ aug-cc-pVQZ//MP2/aug-cc-pVTZ level, respectively) and consequently, this neutral-neutral reaction cannot be considered as a source of formamide in space. Similar conclusions are reached for the reactions of $\mathrm{H}_{2} \mathrm{CO}$ with ionized and protonated hydroxylamine; production of formamide precursors are clearly an exothermic process, but they present an activation barrier. Only if the reaction is initiated by the less stable isomer of protonated hydroxylamine, the barrier lowers to $2.77 \mathrm{kcal} \mathrm{mol}^{-1}$ at the $\operatorname{CCSD}(\mathrm{T}) /$ aug-cc-pVTZ, but, in this case, formation of $\mathrm{HCO}^{+}+\mathrm{NH}_{3} \mathrm{OH}_{2}$ is a barrier-free process.

Our results suggest that the reactions of formaldehyde with hydroxylamine and its ionized and protonated derivatives cannot take place under interstellar conditions and therefore cannot be considered as possible sources of interstellar formamide. These results also show that to establish the importance of a reaction as a possible source of formation of interstellar molecules, not only it is necessary to know its energetic, but also an analysis of the potential energy surface is required to determine the existence of activation barriers.

This negative conclusion should encourage us to search alternative routes for formamide formation in interstellar medium. Other gas-phase ion-molecule reactions, like those of $\mathrm{NH}_{3}^{+}$and $\mathrm{NH}_{4}^{+}$with formic acid, which are found in this work to be exothermic processes, or the reaction between formaldehyde and $\mathrm{NH}_{4}^{+}$proposed by Quan \& Herbst (2007) and Halfen et al. (2011) should be theoretically studied in order to establish their viability in space conditions. In addition, heterogeneous processes on the surface of interstellar grains should also be relevant, as suggest experimental results (Jones et al. 2011; Grim et al. 1989; Garrod et al. 2008).

This research has been supported by the Ministerio de Ciencia e Innovación of Spain (Grant CTQ2010-16864) and by the Junta de Castilla y León (Grant VA077U13).

\section{REFERENCES}

Barrientos, C., Redondo, P., Largo, L., Rayón, V. M., \& Largo, A. 2012, ApJ, 748, 99

Becke, A. D. 1988, JChPh, 88, 1053

Boulet, P., Gilardoni, F., Weber, J., Chermette, H., \& Ellinger, Y. 1999, CP, 244,163

Ceccarelli, C., Loinard, L., Castets, A., Faure, A., \& Lefloch, B. 2000, A\&A, 362,1122

Cernicharo, J., Tercero, B., Fuente, A., et al. 2013, ApJ, 771, L10

Cheung, A. C., Rank, D. M., Townes, C. H., Thornton, D. D., \& Welch, W. J. 1968, PhRvL, 25, 1701

Congiu, E., Chaabouni, H., Laffon, C., Parent, P., Baouche, S., \& Dulieu, F. 2012, JChPh, 137, 054713

Cooper, G. W., Onwo, W. M., \& Cronin, J. R. 1992, GeCoA, 57, 4109

Dunning, T. H. 1989, JChPh, 90, 1007

Frisch, M. J., Trucks, G. W., Schlegel, H. B., et al. 2009, Gaussian 09 (Wallingford, CT: Gaussian, Inc.)

Fukui, K. 1981, AcChR, 14, 363

Garrod, R. T., Widicus Weaver, S. L., \& Herbst, E. 2008, ApJ, 682, 283

Grim, R. J. A., Greenberg, J. M., DeGroot, M. S., et al. 1989, A\&AS, 78,161

Halfen, D. T., Ilyushin, V., \& Ziurys, L. M. 2011, ApJ, 743, 60

Hollis, J. M., Lovas, F. J., Remijan, A. J., et al. 2006, ApJ, 643, L25

Hollis, J. M., Pedelty, J. A., Boboltz, D. A., et al. 2003a, ApJL, 596, L235

Hollis, J. M., Pedelty, J. A., Snyder, L. E., et al. 2003b, ApJ, 588, 353

Hollis, J. M., Snyder, L. E., Suenram, R. D., \& Lovas, F. J. 1980, ApJ, 241, 1001

Hubbard, J. S., Voecks, G. E., Hobby, G. L., et al. 1975, JMolE, 5, 223

Irvine, W. 1998, OLEB, 28, 365

Jones, B. M., Bennett, C. J., \& Kaise, R. I. 2011, ApJ, 734, 78

Kuan, J.-Y., Charnley, S. B., Huang, H.-C., Tseng, W.-L., \& Kisiel, Z. 2003, ApJ, 593,848

Largo, L., Rayón, V. M., Barrientos, C., Largo, A., \& Redondo, P. 2009, CPL, 476, 174

Lee, C., Yang, W., \& Parr, R. G. 1988, PhRvB, 37, 785

Lias, S. G., Bartmess, J. E., Liebman, J. F., et al. 1988, JPCRD, Suppl. 1, 17, 1 
Nguyen, V. S., Abbott, H. L., Dawley, M. M., et al. 2011, JPCA, 115, 841 Nguyen, V. S., Orlando, T. M., Leszczynski, J., \& Nguyen, M. T. 2013, JPCA, 117,2543

Nishi, N., Shinohara, H., \& Okuyama, T. 1984, JChPh, 80, 3898

NIST Chemistry WebBook 2009, http://webbook.nist.gov/

Quan, D., \& Herbst, E. 2007, A\&A, 474, 521

Raghavachari, K., Trucks, G. W., Pople, J. A., \& Head-Gordon, M. 1989, CPL, 157,479

Rubin, R. H., Swenson, G. W., Benson, R. C., Tigelaar, H. L., \& Flygare, W. H. 1971, ApJ, 169, L39
Saladino, R., Crestini, C., Pino, S., Costanzo, G., \& Di Mauro, E. 2012, Phys. Live Rev., 9, 84

Snow, J. L., Orlova, G., Blagojevic, V., \& Bohme, D. K. 2007, JAChS, 129, 9910

Snyder, L. E., Lovas, F. J., Hollis, J. M., et al. 2005, ApJ, 619, 914

Synder, L. E., Buhl, D., Zuckerman, B., \& Palmer, P. 1969, PhRvL, 22, 679

Winnewisser, G., \& Churchwell, E. 1975, ApJ, 200, L33

Woon, D. E. 2001, IJQC, 88, 226

Woon, D. E., \& Dunning, T. H. 1993, JChPh, 98, 1358

Zheng, W., \& Kaiser, R. I. 2010, JPCA, 114, 5251 